\title{
A Simple Process to Prepare Silica Aerogel Microparticles from Rice Husk Ash
}

\author{
R. S. Kumar, M. Vinjamur, and M. Mukhopadhyay
}

\begin{abstract}
Biocompatible silica aerogel microparticles are promising drug delivery vehicles because of their large surface area and open pore structures. A simple process has been developed in this work to prepare silica aerogel microparticles from rice husk ash, using water-in-mineral oil emulsion for sol-gel, followed by aging in ethanol to strengthen gel network and drying with $\mathrm{scCO}_{2}$. This process obviates drawback of current methods for silica aerogels. The effects of speed of agitation of water-oil mixture, sol-to-oil ratio and surfactant concentration have been investigated on particle size and size distribution, BET surface area, cumulative pore volume and pore diameter. A surface area of $654 \mathrm{~m}^{2} / \mathrm{g}$, higher than the values reported for similar materials, could be obtained.
\end{abstract}

Index Terms-Rice husk ash, silica aerogel microparticles, supercritical carbon dioxide, water-in-oil emulsion.

\section{INTRODUCTION}

Aerogels are a diverse class of porous, solid materials composed of a network of interconnected mono structures that exhibit porosity up to $95-99 \%$, high surface area $\left(200-1000 \mathrm{~m}^{2} / \mathrm{g}\right)$, pore size $(1-100 \mathrm{~nm})$ and low density $\left(0.003-0.5 \mathrm{~g} / \mathrm{cm}^{3}\right)$. These unique properties of aerogels attracted many researchers to explore them as drug delivery vehicles [1]-[5].

Most commonly used raw materials for preparation of silica aerogels are tetraethylorthosilicate (TEOS), tetramethylorthosilicate (TMOS), and sodium silicate solution (water glass). These raw materials are more expensive and also carcinogenic. Therefore, for large-scale industrial production and for drug delivery applications, it is preferable to replace these conventional inorganic-based raw materials with an inexpensive, biocompatible, nontoxic and readily available bio-source as the raw material. Rice husk, an agricultural waste from rice mill industry, has a high silica content $(\sim 80-90 \%)$ and is easily available in large quantity [6]. Accordingly, it is a good alternative to the conventional materials and has a great potential as a bio-source for large scale production of silica aerogel microparticles.

The process to make aerogels includes a sol-gel step to prepare wet gels which are carefully dried in the subsequent step to preserve the pore structure and surface area. Though aerogels are composed of nanoparticles which are connected in a three dimensional open pore network, they are produced in a variety of forms such as monolith, powder, beads, blanket, flexible sheets etc. The preparation of monolith is much easier compared to aerogel particles [7].

However, aerogel microparticles prepared by direct

Manuscript received July 2, 2013; revised September 1, 2013.

The authors are with Indian Institute of Technology Bombay, Mumbai 400076, India (e-mail: sureshrs02@gmail.com, madhu@ iitb.ac.in, mm@iitb.ac.in). methods offer several advantages over monoliths. For example, in pharmaceutical industry, aerogel powder is produced by crushing monolith, which consumes high energy and also, crushing may cause loss of textural properties of aerogels. Hence it is essential to prepare aerogel microparticles for drug delivery applications by direct synthesis method, which offers excellent control over physicochemical properties of aerogels [8].

The critical step in preparation of aerogels is drying of wet gels. The quality of aerogels obtained is poor if wet gels are dried under atmospheric pressure. During atmospheric drying, the porous structure of the gels collapses due to capillary pressure resulting in shrinkage of the gel network and thereby reduction of porosity. This happens as a result of interfacial tension between the vapor and the liquid phases in the pores. This can be obviated by supercritical drying, that is, by drying in the absence of a vapor-liquid interface [9]. The use of surface modification agents can modify mechanical properties of wet gels in order to circumvent destruction of pore structure during drying under atmospheric or subcritical conditions [10], [11]. However, this has a drawback that the surface modification chemicals are carcinogenic and expensive. On the other hand, the supercritical carbon dioxide-dried aerogels exhibit superior physicochemical characteristics, as compared to the atmospheric pressure-dried xerogels [12]. Supercritical carbon dioxide $\left(\mathrm{scCO}_{2}\right)$ drying is a green technology and does not require any surface modification of wet alcogels. By operating the process in a closed cycle, the wastage of carbon dioxide can be minimized.

In the present work, a simple process has been proposed for preparation of silica aerogel microparticles from a bio-source, such as, rice husk ash using water-in-mineral oil emulsion. This method is simple and it eliminates the requirement of any expensive surface modification chemicals and usage of mechanical separation methods like filtration and centrifugation. The wet alcogels are dried in $\mathrm{scCO}_{2}$ under suitable conditions. The aerogels are then characterized using scanning electron microscopy (SEM) for micro structural analysis and nitrogen adsorption desorption isotherms analysis for specific surface area, pore volume and pore size. The effects of gelation process parameters such as speed of agitation (400 rpm to $1200 \mathrm{rpm}$ ) and oil-to-sol ratio (1:1 to $3: 1)$, and surfactant concentration $(0-2 \%)$ have been investigated to ascertain the optimum condition for the gelation process.

\section{MATERIALS AND METHODS}

\section{A. Materials}

Rise husk ash obtained from Department of Energy 
Science and Technology, IIT Bombay. Sodium hydroxide (Merck, India), Hydrochloric acid (35\%, Merck, India), Ethanol (99.9\% purity; Merck, India), $\mathrm{CO}_{2}$ of $99 \%$ purity (Med Gas N Equipment, India), Distilled water, Kerosene (SDFCL, India), Span 80(sigma Aldrich, USA) were used as received.

\section{B. Preparation of Silica Aerogel Microparticles}

A schematic flow chart for preparation of silica aerogel microparticles from rice husk ash is proposed as shown in Fig 1. Properly cleaned rice husk was burned at $700{ }^{\circ} \mathrm{C}$ in a muffle furnace for $6 \mathrm{~h}$ to get rice husk ash. $5 \mathrm{~g}$ of rice husk ash was mixed with $150 \mathrm{~mL}$ of $1 \mathrm{~N}$ sodium hydroxide aqueous solution. The mixture was refluxed for $1 \mathrm{~h}$ at $90{ }^{\circ} \mathrm{C}$. The solution was filtered and stored in a refrigerator for further usage.

A $5 \mathrm{ml}$ sample of sodium silicate solution was taken from the stock solution and poured into $15 \mathrm{ml}$ kerosene at a time and stirred for a specific time. The $\mathrm{pH}$ of the solution was adjusted to 6-7 by dropwise addition of hydrochloric acid under constant stirring speed to form silica gel. The time required for gelation is approximately two minutes after sol solution was neutralized. Agitation was continued for another one hour to obtain wet gel microparticles. The prepared gel was aged at $40{ }^{\circ} \mathrm{C}$ for $1 \mathrm{~h}$ under sealed condition. Kerosene, water, $\mathrm{NaCl}$ and other impurities were separated from the gel by solvent exchange with dilute and pure ethanol in 3-4 stages. The dilute ethanol (50\% and $75 \%)$ was used to avoid any structural shrinkage during the solvent exchange. Totally, ethanol exchange was done four times and aged at $40{ }^{\circ} \mathrm{C}$. The total time of aging was $38 \mathrm{~h}$. The wet alcogels were then dried in $\mathrm{scCO}_{2}$ at $150 \mathrm{bar}, 50{ }^{\circ} \mathrm{C}$ and $3 \mathrm{lpm}$ (liter per minute) for $6 \mathrm{~h}$. The effects of speed of agitation (400-1200 rpm), oil-to-sol ratio $(1: 1$ to $3: 1)$ and surfactant concentration (0-2 wt \%) were studied on textural and morphological properties of silica microparticles.

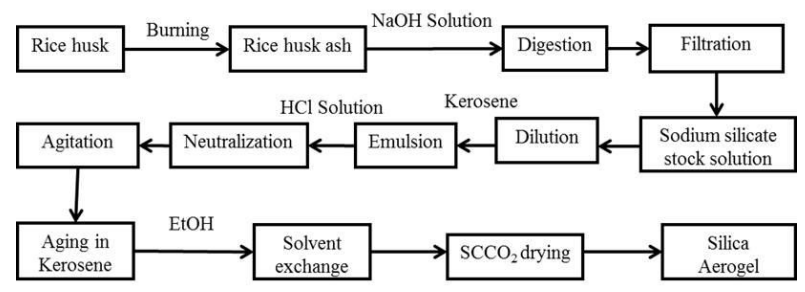

Fig. 1. Schematic flowchart of silica aerogel preparation from rice husk ash

\section{Supercritical Drying of Wet Alcogels}

A schematic diagram of the supercritical drying set-up is shown in Fig. 2. The set-up consists of a $500 \mathrm{ml}$ extraction vessel, a pump, a chiller and a PLC system to control pressure and temperature. The alcogels were poured into a small steel container and placed into the extraction vessel. A filter cloth was inserted in the vessel to support the steel container and for uniform distribution of $\mathrm{scCO}_{2}$ throughout the vessel. Excess ethanol was added to prevent any shrinkage due to evaporation of ethanol in the alcogels network before exposure to $\mathrm{scCO}_{2}$. The extractor was heated to $50{ }^{\circ} \mathrm{C}$ by an external electrical heater. Once the desired temperature was attained in the extraction vessel, $\mathrm{CO}_{2}$ cylinder was slowly opened and the extractor was pressurized up to the cylinder pressure. Then $\mathrm{CO}_{2}$ was fed by a high-pressure plunger pump to the extractor containing the gels until the desired working pressure of 150 bar was reached. The $\mathrm{CO}_{2}$ was preheated using a heating coil around the extraction vessel, as shown in Fig. 2. The temperature and pressure of the system were automatically maintained by using the PLC system. Then, the release of $\mathrm{scCO}_{2}$ from the extractor was started by opening micrometering valve (with heating being provided) and the constant flow rate of $3 \mathrm{lpm}$ was maintained throughout drying process at constant pressure and temperature. The alcogels were dried under these operating conditions for $6-8 \mathrm{~h}$ to assure complete removal of the solvent. The time of pressurization and depressurization is not included in the total drying time. Finally, $\mathrm{scCO}_{2}$ in the vessel was depressurized slowly within 60-90 $\mathrm{min}$ at constant temperature $\left(50{ }^{0} \mathrm{C}\right)$ until atmospheric pressure was reached. The separating vessel at atmospheric pressure, connected at the outlet of the micrometering valve, was kept in a container filled with ice cubes to condense ethanol solvent vapors carried by $\mathrm{CO}_{2}$.

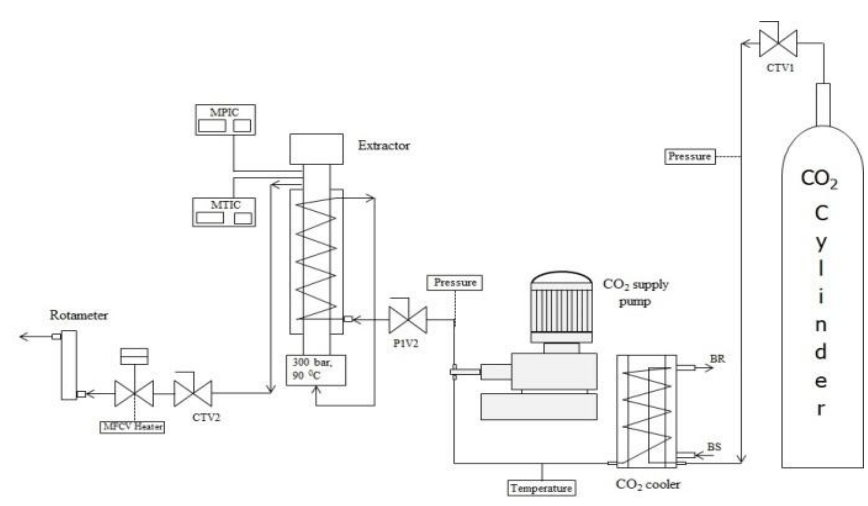

Fig. 2. Schematic diagram of experimental setup for supercritical $\mathrm{CO}_{2}$ drying

\section{Characterization of Aerogels}

The particle size distribution of wet gel microparticles were measured using a Laser Diffraction Particle Size Analyzer (LS 13 320, Beckman Coulter) equipped with a software to measure particle size and particle size distribution. Particle concentration $>8-10 \%$ was maintained during all measurements. The inverted optical microscope was used to observe the shape and size of wet gel microparticles. The measurements of specific surface area, pore volume and pore diameter were performed at various partial pressures $(0.01<$ $\left.p / p_{0}<1\right)$ using Micro Meritics, ASAP 2020 BET instrument. The specific surface area of the aerogels is determined by means of adsorption and desorption isotherms of nitrogen. Prior to BET analysis, a known quantity of aerogel sample was heated at $200{ }^{0} \mathrm{C}$ for $3 \mathrm{~h}$ under vacuum to remove physically bonded impurities from the surface of the aerogel microparticles. The specific surface area $\left(\mathrm{A}_{\mathrm{BET}}\right)$ was determined by the BET (Brunauer-Emmett-Teller) multipoint method. The cumulative pore volume $\left(\mathrm{V}_{\mathrm{p}}\right)$ and average pore size were estimated using the $\mathrm{BJH}$ (Barrett-Joyner-Halenda) adsorption cumulative pore volume method. The internal microstructure of the aerogel microparticles was studied by field emission gun scanning electron microscopy (FEG SEM, JSM-7600F, Hitachi, Tokyo, Japan). Before the micrographs were taken, the samples were sputtered with a gold layer. 


\section{RESUlTS AND DisCUSSION}

\section{A. Separation of Wet Gel Microparticles}

Conventionally a vegetable oil is used as a continuous phase for the preparation of water-in-oil emulsion. The subsequent separation of oil from the gel particles is difficult. In general, the wet-gel microparticles are separated from the oil phase by separation methods such as filtration or centrifugation during which there may be a possibility of collapse of the pore structure of the wet gels. To avert this collapse, a mineral oil, namely, low-odor kerosene was used instead of a vegetable oil as a continuous phase in this work. The properties of kerosene such as low viscosity, low density, and low boiling point (compared to vegetable oil) facilitate the separation of the gel and kerosene phases. After gelation was completed, the gel and kerosene phases were allowed to settle. Kerosene forms the upper layer, which was discarded. The gel phase was aged in four steps with ethanol, the concentration of ethanol in a step being higher than the previous step. During aging, kerosene, water and $\mathrm{NaCl}$ were removed from the gel phase. The slow exchange of water in the pores with increasing concentrations of ethanol avoids shrinkage of gel network during the exchange and also ensures complete removal of kerosene as well as water. Any traces of kerosene, if present in the wet gels, were removed completely during their drying with $\mathrm{scCO}_{2}$. One of the advantages of present process is that the gel microparticles are separated from the oil phase without using any mechanical separation step.

\section{B. Effects of Gelation Process Parameters}

\section{1) Effect of speed of agitation}

The effect of speed of agitation on wet particle size distribution is shown in Table I. The average mean particle diameter of microparticles varies from $166 \mu \mathrm{m}$ at $400 \mathrm{rpm}$ to $116 \mu \mathrm{m}$ at $1200 \mathrm{rpm}$. It is evident from the Table 1 that the particle size distribution of particles is broad for all speeds. This breadth is attributed to the increasing viscosity of the dispersed phase (sol solution) during formation of the gel particles. ${ }^{[8]}$ The speed of agitation plays a major role in controlling the mean particle size and textural properties of the aerogel microparticles. The smallest average particle size and highest BET surface area were obtained for the silica aerogel microparticles prepared at $1200 \mathrm{rpm}$ and 1:3 sol-to-oil ratio. Therefore these parameters have been considered for further study.

TABLE I: VARIATION OF AVERAGE PARTICLE SIZE OF WET GEL MICROPARTICLES WITH SPEED OF AGITATION

\begin{tabular}{|c|c|c|c|c|}
\hline \multirow[t]{2}{*}{ Range } & \multicolumn{3}{|c|}{ 1:3 sol-to-oil ratio } & \multirow{2}{*}{$\begin{array}{c}1: 2 \\
\text { sol-to-oil ratio } \\
1200 \mathrm{rpm}\end{array}$} \\
\hline & $\begin{array}{l}400 \\
\mathrm{rpm}\end{array}$ & $\begin{array}{l}800 \\
\mathrm{rpm}\end{array}$ & $\begin{array}{l}1200 \\
\mathrm{rpm}\end{array}$ & \\
\hline $\begin{array}{c}\text { Average } \\
\text { diameter }(\mu \mathrm{m})\end{array}$ & 166.8 & 152.8 & 116.6 & 250.5 \\
\hline $\mathrm{D}_{10}(\mu \mathrm{m})$ & 73.1 & 61.8 & 54.5 & 50.3 \\
\hline $\mathrm{D}_{25}(\mu \mathrm{m})$ & 106.7 & 94.0 & 77.9 & 73.3 \\
\hline $\mathrm{D}_{50}(\mu \mathrm{m})$ & 158.8 & 142.1 & 109.3 & 103.9 \\
\hline $\mathrm{D}_{75}(\mu \mathrm{m})$ & 219.9 & 203.7 & 147.7 & 144.0 \\
\hline $\mathrm{D}_{90}(\mu \mathrm{m})$ & 273.8 & 261.5 & 190.3 & 227.2 \\
\hline
\end{tabular}

Fig. 3 shows the inverted optical microscope images of wet gel microparticles in kerosene mixed with $2 \%$ span-80 prepared at a stirring speed of $1200 \mathrm{rpm}, 1: 3$ sol-to-oil ratio and $1 \mathrm{~h}$ stirring time. The particles formed were perfectly spherical in shape. The particles became smaller as the speed of agitation was raised from $400 \mathrm{rpm}$ to $1200 \mathrm{rpm}$. At low agitation speed, some of the particles were not spherical as shown in Fig. 3 (c). These particles were irregular in shape and usually bigger than spherical particles.
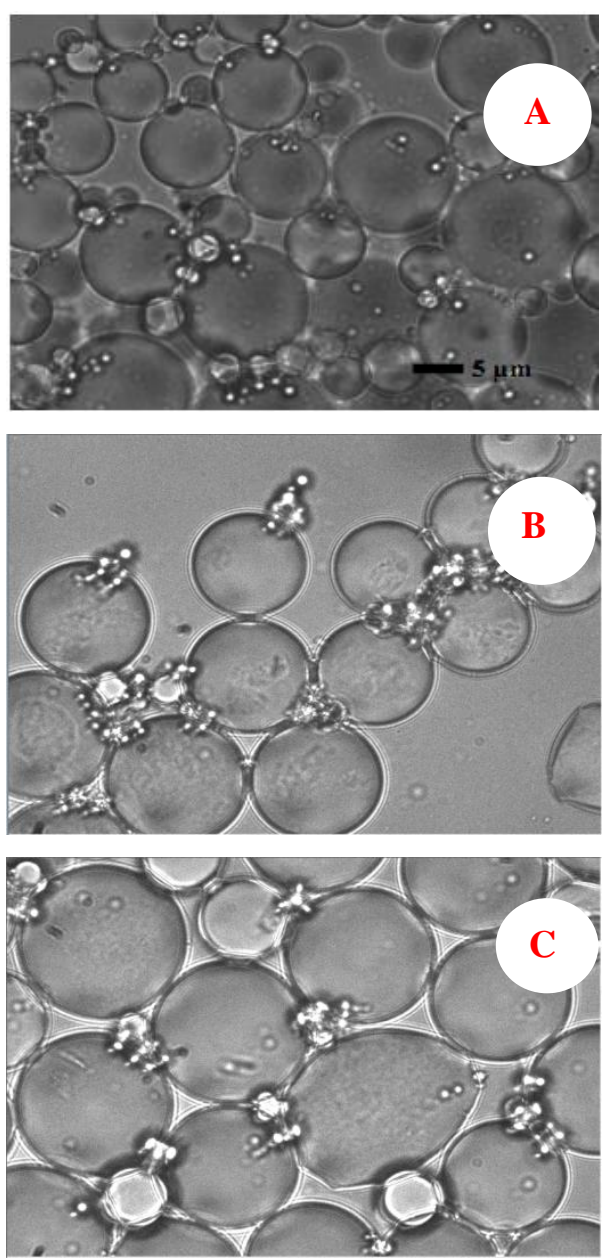

Fig. 3. Inverted optical microscope images of wet silica aerogel microparticles in kerosene prepared at 1:3 sol to oil ratio and 2\% span-80 (a) $1200 \mathrm{rpm}$, (b) $800 \mathrm{rpm}$ and (c) $400 \mathrm{rpm}$ at a magnification of x40.

Table II shows variation of BET specific surface area, cumulative pore volume and average pore diameter of silica aerogel microparticles with speed of agitation from $400 \mathrm{rpm}$ to $1200 \mathrm{rpm}$ for $1: 3$ sol-to-oil ratio and at $1200 \mathrm{rpm}$ for $1: 2$ sol-to-oil ratio. As speed of agitation is raised from 400 to $1200 \mathrm{rpm}$, the specific surface area and cumulative pore volume increase from about 360 to $640 \mathrm{~m}^{2} / \mathrm{g}$ and 0.49 to 1.38 $\mathrm{cm}^{3} / \mathrm{g}$ respectively. The latter area is more than the reported specific surface area of aerogels made from similar materials [12]. It is presumed that the new process for preparation of highly porous silica aerogel microparticles gives high specific surface area owing to the microparticles created during gelation - these particles have high external surface area in addition to high internal surface area. At higher speeds for 1:3 sol-to-oil ratio, smaller microparticles of aerogels are produced than at lower speeds. The smaller particles have higher external surface area per unit mass than the bigger particles. Thus larger specific surface area is obtained for microparticles produced at higher speeds. The cumulative pore volume of aerogels prepared at 800 and 400 
rpm are similar even though average pore diameters are different. From the BJH pore size distribution (graphs not shown here) it is confirmed that, all aerogel microparticles consist of both meso and macro pores. For both the sol-to-oil ratios, at $1200 \mathrm{rpm}$, the average pore diameter is larger than $400 \mathrm{rpm}$ and $800 \mathrm{rpm}$.

TABLE II: TEXTURAL PROPERTIES OF AEROGEL MiCROPARTIClES PREPARED UNDER DIFFERENT PROCESS CONDITIONS.

\begin{tabular}{cllll}
\hline $\begin{array}{l}\text { Sol-to-oil } \\
\text { ratio }\end{array}$ & $\begin{array}{l}\text { Speed of } \\
\text { stirrer }\end{array}$ & $\begin{array}{l}\text { BET surface } \\
\text { area }\left(\mathrm{m}^{2} / \mathrm{g}\right)\end{array}$ & $\begin{array}{l}\text { BJH pore } \\
\text { volume }\left(\mathrm{cm}^{3} / \mathrm{g}\right)\end{array}$ & $\begin{array}{l}\text { Average pore } \\
\text { diameter } \\
(\mathrm{nm})\end{array}$ \\
\hline $1: 3$ & 1200 & 640 & 1.38 & 7.6 \\
& 800 & 558 & 0.49 & 4.8 \\
& 400 & 363 & 0.49 & 3.8 \\
\hline $1: 2$ & 1200 & 327 & 0.81 & 8.4
\end{tabular}

The internal structure of silica aerogel microparticles, prepared at $1200 \mathrm{rpm}$ and 1:3 sol-to-oil ratio, is captured by SEM (see Fig. 4). The SEM image reveals that the silica aerogel microparticles are highly porous consisting of both meso as well as macro pores. Fig. 4 shows that the aerogel microparticles have sponge-like internal structure and a three dimensional cross-linked network.

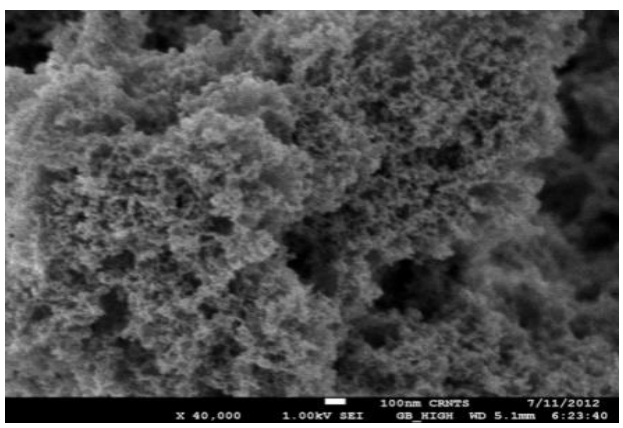

Fig. 4. SEM image of silica aerogel microparticles prepared at $1200 \mathrm{rpm}, 1: 3$ sol-to-oil ratio.

Fig. 5. shows nitrogen adsorption isotherms for various aerogels synthesized at different speeds of agitation. The quantity of nitrogen adsorbed on $1200 \mathrm{rpm}$-aerogels is much higher than that at 400 and $800 \mathrm{rpm}$, as shown in Fig. 5. Therefore it is confirmed that these aerogels have larger specific surface area than others. The characteristics of adsorption isotherms of aerogels prepared at 400 and $800 \mathrm{rpm}$ are similar in nature; these isotherms belong to category IV, which indicates meso porous structure and both mono and multilayer nitrogen adsorption took place. The intermediate flat region in all isotherms and the BET constant $\left(\mathrm{C}_{\mathrm{BET}}\right)$ for all three samples lie in the range of 60 to 95 , which is an indication of formation of monolayer [13].

\section{2) Effect of sol-to-oil ratio}

The effect of volume ratio between sol solution and oil phase on particle size distribution and textural properties of aerogel microparticles were studied and results are presented in Tables I and II. Two sol-to-oil ratios, 1:2 and 1:3, were considered. For both ratios, total volume of the oil and the sol solutions was $20 \mathrm{ml}$ and agitation speed was $1200 \mathrm{rpm}$. For the 1:3 sol-to-oil ratio, the mean particle size obtained was smaller than 1:2 sol-to-oil phase ratio, as can be seen from Table I, which could be due to lower viscosity of the former than the latter.
Table II shows variation of BET specific surface area, cumulative pore volume and average pore diameter of silica aerogel microparticles for 1:3 sol-to-oil ratio and 1:2 sol-to-oil ratio at $1200 \mathrm{rpm}$. It can be seen that for $1: 2$ sol-to-oil ratio, the particles were formed with lower BET specific surface area compared to 1:3 sol-to-oil ratio.

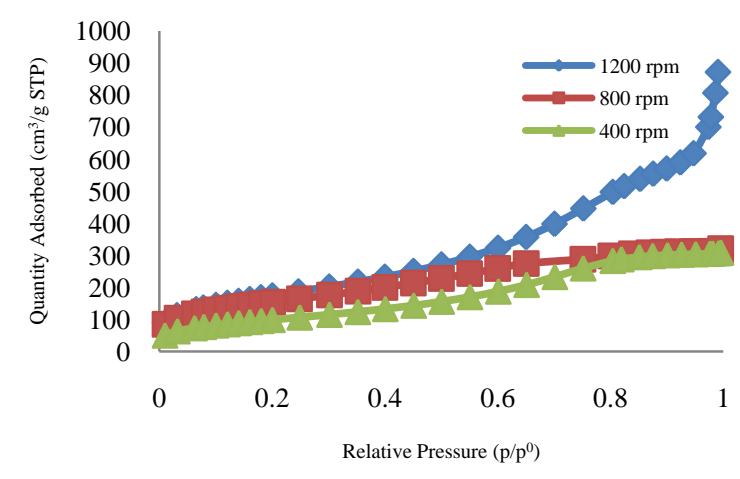

Fig. 5. BET nitrogen adsorption isotherm linear plot

\section{3) Effect of surfactant}

Surface active agent plays a major role in producing non agglomerated spherical aerogel microparticles. Span 80 (with HLB of 4.3) was used as an emulsifying agent, which is highly soluble in kerosene phase. Gel particles were agglomerated and were sticking to the walls of the vessel during agitation when there was no surfactant or less surfactant $(1 \%)$ was used. Therefore surfactant concentration was increased to $2 \%$ and it was physically observed that no agglomeration of particles took place during agitation. The role of surfactant can be clearly visualized as particles are not agglomerated and separated from each other as shown in Fig. 4.

\section{CONCLUSION}

Silica aerogel microparticles were synthesized from a bio source, rice husk ash, which is easily available. A simple process has been developed for preparation of silica aerogel microparticles by water-in-mineral oil emulsion method using kerosene as the oil phase; the wet particles were dried using $\mathrm{scCO}_{2}$. Kerosene was completely removed from the particles, most of it prior to drying, without any mechanical separation method. The typical aerogel microparticles, dried with $\mathrm{scCO}_{2}$ at $150 \mathrm{bar}$ and $50{ }^{\circ} \mathrm{C}$ for $6-8 \mathrm{~h}$, have high BET specific surface area of $640 \mathrm{~m}^{2} / \mathrm{g}$ and pore volume of 1.38 $\mathrm{cm}^{3} / \mathrm{g}$, which are more than the reported values for similar materials. The smallest average mean particle size of 116.6 $\mu \mathrm{m}$ was observed for wet silica gel microparticles prepared at $1200 \mathrm{rpm}$ with 1:3 sol-to-oil ratio and $2 \%$ span-80. The average mean particle size of silica aerogel microparticles increases as speed of agitation and sol-to-oil ratio decreases.

\section{REFERENCES}

[1] H. D. Gesser and P. C. Goswami, "Aerogels and related porous materials," Chemical Reviews, vol. 89, no. 4, pp. 765-788, 1989.

[2] I. Smirnova, J. Mamic, and W. Arlt, "Adsorption of Drugs on Silica Aerogels," Langmuir; vol. 19, no. 20, pp. 8521-8525, 2003.

[3] G. Caputo, M. Scognamiglio, and I. D. Marco, "Nimesulide adsorbed on silica aerogel using supercritical carbon dioxide," Chemical Engineering Research and Design, pp. 255-260, 2010. 
[3] G. Caputo, M. Scognamiglio, and I. D. Marco, "Nimesulide adsorbed on silica aerogel using supercritical carbon dioxide," Chemical Engineering Research and Design, pp. 255-260, 2010.

[4] N. H. M. Yunos, H. Hamdan, and L. S. Ling, "Piperine loaded silica aerogel and silica xerogel as NANO-enabled drug delivery system," World Appl. Sci. J, vol. 9, no. 9, pp. 6-16, 2010.

[5] I. Smirnova, S. Suttiruengwong, and W. Arlt, "Aerogels: tailor-made carriers for immediate and prolonged drug release," KONA, vol. 23, pp 86-97, 2005.

[6] J. P. Nayak and J. Bera, "Preparation of silica aerogel by ambient pressure drying process using rice husk ash as raw material," Trans. Indian Ceram. Soc, vol. 68, no. 2, pp. 91-94, 2009.

[7] S. K. Hong, M. Y. Yoon, and H. J. Hwang, "Fabrication of Spherical Silica Aerogel Granules from Water Glass by Ambient Pressure Drying," Journal of the American Ceramic Society, vol. 94 no. 10, pp. 3198-3201, 2011

[8] M. Alnaief and I. Smirnova, "In situ production of spherical aerogel microparticles," The Journal of Supercritical Fluids, vol. 55, no. 3, pp 1118-1123, 2011.

[9] A. Bisson, A. Rigacci, D. Lecomte, E. Rodier, and P. Achard, "Drying of Silica Gels to Obtain Aerogels: Phenomenology and Basic Techniques," Drying Technology, vol. 21 no. 4, pp. 593-628, 2003.

[10] F. Shi, L. Wang, and J. Liu, "Synthesis and characterization of silica aerogels by a novel fast ambient pressure drying process," Materials Letters, vol. 60, pp. 3718-3722, 2006.

[11] A. Tadjarodi, M. Haghverdi, and V. Mohammadi, "Preparation and characterization of nano-porous silica aerogel from rice husk ash by drying at atmospheric pressure," Materials Research Bulletin, vol 47, pp. 2584-2589, 2012.

[12] Q. Tang and T. Wang, "Preparation of silica aerogel from rice hull ash by supercritical carbon dioxide drying," The Journal of Supercritical Fluids, vol. 35, no. 1, pp. 91-94, 2005.

[13] R. A. Oweini and H. El-Rassy, "Surface characterization by nitrogen adsorption of silica aerogels synthesized from various $\mathrm{Si}(\mathrm{OR}) 4$ and R"Si(OR') $)_{3}$ precursors," Applied Surface Science, vol. 257, pp. 276-281, 2010

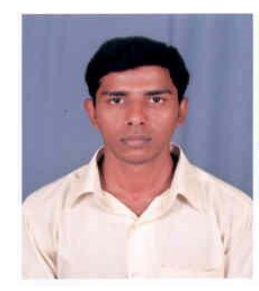

Suresh Kumar R. was born in Bangalore, India, on March, 1, 1984.He received the Diploma from Sri Jayachamarajendra (Govt.) Polytechnic Bangalore, India, B.E. degree from Siddaganga Institute of Technology, Tumkur, India and M.Tech degree from National Institute of Technology Karnataka, Surathkal, India with the dissertation "Synthesis and Characterization of Temperature-Sensitive Poly ( $\mathrm{N}$-isoprophylacrylamide) Micro/Nano Hydrogels.” He worked at Cipla limited, Bangalore, India for 1 year as a management trainee after his B.E. degree. Currently he is pursuing his doctor of philosophy in the department of chemical engineering at IIT Bombay, Mumbai, India. His current interests include preparation of aerogels from natural bio sources and their characterization for drug delivery applications.

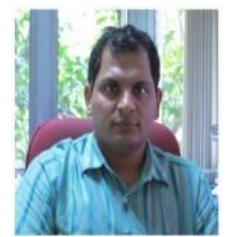

Madhu Vinjamur obtained his B.Tech degree from IIT Kharagpur, M.Tech from Institute of Chemical Technology, Mumbai (formerly UDCT) and PhD from Drexel University, Philadelphia, USA. His research interests include supercritical fluid processing for producing ultra-fine and nanoparticles for drug delivery, drying of foods and polymeric coatings.

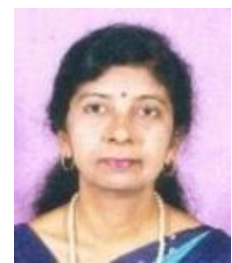

Mamata Mukhopadhyay obtained her B.Ch.E. degree from Jadavpur University, Kolkata, M.Tech. from IIT Kharagpur and PhD from the Ohio State University, USA. Her research and development interests include supercritical fluid extraction, processing with supercritical fluids, $\mathrm{CO}_{2}$-based processes for production of nanoparticles, food process engineering and pressurized hot water extraction, leading to techn- ology development, pilot plant design and demonstration and technology transfer 